Background: The life expectancy of patients with cystic fibrosis (CF) is largely dependent on the pulmonary disease severity and progress. Malnutrition may be an important complicating factor in active and chronic lung disease.

Aims: The focus of this study was to investigate several inflammatory markers in pancreatic-insufficient $C F$ patients with different enzyme treatment regimens.

Metbods: CF patients with pancreatic insufficiency were examined at a time of symptomatic exacerbation of their lung disease. Group A $(n=11)$ regularly received microspheric enzymes. Group B $(n=8)$ were treated with enzymes during the hospitalization period only and demonstrated the presence of malnutrition. Inflammatory markers in the sputa (neutrophil elastase activity, interleukin-8 and tumour necrosis factor- $\alpha$ levels) and in the peripheral blood (plasma malondialdehyde (MDA), lymphocyte response to $\mathrm{PHA}$, and the cell sensitivity to steroid suppression) have been investigated.

Results: During acute lung exacerbation, group B demonstrated reduced levels of lymphocyte proliferation. This parameter was normalized after combined antibiotic and pancreatic enzyme therapy. Simultaneously, plasma MDA in group B markedly increased following treatment. For this group, a significant positive linear association between values of plasma MDA and lymphocyte proliferation has been observed. For group A, neither the same correlation nor changes in MDA levels and lymphocyte proliferation have been found.

Conclusions: Our data indicate that acute lung exacerbation in malnourished $\mathrm{CF}$ patients may be associated with alteration in T-lymphocyte activity. Adequate therapy normalizes lymphocyte function but results in systemic oxidative stress.

Key words: Cystic fibrosis, Inflammatory response, Oxidative stress, Pancreatic insufficiency

\section{Improvement of nutrient absorption may enhance systemic oxidative stress in cystic fibrosis patients}

\author{
Galina V. Shmarina, ${ }^{1, C A}$ Alexander L. Pukhalsky, ${ }^{1}$ \\ Svetlana N. Kokarovtseva, ${ }^{1}$ Daria A. Pukhalskaya, ${ }^{1}$ \\ Elena A. Kalashnikova,' Nikolaï I. Kapranov ${ }^{2}$ and \\ Natalia J. Kashirskaja ${ }^{2}$
}

${ }^{1}$ Laboratory of Immunogenetics, and ${ }^{2}$ Department of Cystic Fibrosis, Research Centre for Medical Genetics, 1 Moskvorechie Street, Moscow, 115478, Russia

\footnotetext{
${ }^{\mathrm{CA}}$ Corresponding Author

Fax: +7 0953240702

E-mail: vikgor@arstel.ru
}

\section{Introduction}

The life expectancy of patients with cystic fibrosis (CF) is largely dependent on the pulmonary disease severity and progress. Abnormal function of CF transmembrane regulator (CFTR) results in obstructive pulmonary process due to accumulation of thick, viscous mucus, which leads to impaired mucociliary clearance. ${ }^{1}$ During the first years of life, young children with CF are colonized and develop pneumonia secondary to Staphylococcus aureus, Haemophilus influenzae or, less commonly, Klebsiella pneumoniae. ${ }^{2}$ The pulmonary infections incite an intense inflammatory response characterized by a marked influx of neutrophils into the lung, and elevation in inflammatory mediators such as tumour necrosis factor- $\alpha$ (TNF- $\alpha$ ), interleukin (IL)-1 $\beta$, IL-6, IL-8, and leukotriene $B_{4} \cdot{ }^{3}$
Lung inflammation is greatly amplified after Pseudomonas aeruginosa infection. Colonization with the pathogen initiates exuberant host immune response with a 1000-fold increase in the numbers of activated neutrophils releasing excessive amounts of elastase and oxidants, which may directly damage pulmonary epithelium. ${ }^{4-6}$ A consequence of the persistent inflammation and repeated cycles of infection is progressive lung damage and pulmonary fibrosis. ${ }^{7}$

The other hallmark CF manifestation is exocrine pancreatic dysfunction, resulting in malnutrition, growth failure and specific nutritional deficiencies. These abnormalities clearly contribute to acute and chronic lung disease. Thus, the occurrence of malnutrition seems to be associated with respiratory muscle weakness, impaired repair of airway walls and immune dysfunction. ${ }^{8-11}$ Among specific nutritional 
deficiencies, the most common ones involve fatsoluble vitamins (antioxidants) and polyunsaturated fatty acids (PUFAs). ${ }^{12}$ There are considerable clinical implications of these deficiencies. Malabsorption of fat-soluble antioxidants exacerbates systemic oxidative stress, increases free radical tissue damage and promotes excessive inflammatory response. A number of studies have added information about the last effect, showing that unopposed reactive oxygen species (ROS) may directly activate the transcription nuclear factor- $\kappa \mathrm{B}$, which induces expression of genes involved in inflammatory and acute phase response. ${ }^{13}$ In addition, increased ROS generation and, as a consequence, elevated fatty acid oxidation may aggravate PUFA deficiency, which is associated with alteration in membrane composition and impairment of immune cell activity. ${ }^{14}$ Most patients with CF achieve adequate nutrient absorption with intakes of pancreatic enzymes; others, despite huge doses, remain symptomatic. It seems that the extent of compensation of abnormalities associated with pancreatic insufficiency is individual and depends on patient genotype and dietary management.

This study aimed to compare inflammatory markers in pancreatic-insufficient CF patients with different enzyme treatment regimens. The first patient group regularly received enteric-coated enzyme microspheres/mini-tablet preparations, and the second was treated with enzyme supplements during the period of hospitalization only. The patients were examined at a time of symptomatic exacerbation of their lung disease, then again after 2 weeks of antibiotic treatment.

\section{Materials and methods}

\section{Patient assessment}

Nineteen patients from the Cystic Fibrosis Department of the Research Center for Medical Genetics (Moscow) were enrolled in the study. Cystic fibrosis was diagnosed by increased chloride concentrations (>60 mmol/l) in a sweat test and typical clinical symptoms of the disease, and/or detection of mutations in both CFTR alleles. All subjects had evidence of pancreatic insufficiency requiring enzyme replacement therapy. The patients were divided into two groups depending on their previous history. Group A ( $n=11$ ) consisted of individuals who had regularly received currently recommended lipase/protease intake for each kilogram of body weight. Eight patients were treated with microspheric enzymes during the period of hospitalization only (group B). The reasons for irregular pancreatic enzyme treatment were social, including the tardy receiving of government support, infrequent follow-up at the centres, and parent's preference. The patients were recruited at a time of symptomatic exacerbation of their lung disease, defined as a marked increase of C-reactive protein, by weight loss, anorexia, increased cough, increased sputum production, fever with and without new lung infiltrates, and deterioration of oxygen saturation and pulmonary function. Patients with acute pulmonary exacerbation were treated with basic therapy (microspheric enzymes, multivitamins, high colory diet, mucolytics) and antibiotics. Antibacterial treatment depended on the microbiology analysis of the sputum. In the case of $P$. aerugenosa infection, cephalosporins of third generation in combination with aminoglycosids or ciprofloxacin were prescribed. The study was approved by the local ethics committee.

Information regarding demographic data, pulmonary function test results (forced expiratory volume in $1 \mathrm{sec}$ and forced vital capacity), nutritional status (assessed by the weight to height ratio $(\mathrm{W} / \mathrm{H})$ ), and respiratory secretion cultures was obtained from the Cystic Fibrosis Department of the Research Center for Medical Genetics. Results of pulmonary tests and nutritional status assessment are expressed as a percentage of predicted values for age, sex, and height.

\section{Blood collection and sputum processing}

Blood was collected in tubes with heparin $(25 \mathrm{IU} / \mathrm{ml})$ by venopuncture.

The weight of each sputum sample was calculated. The same weight of phosphate-buffered saline without $\mathrm{Ca}^{2+}$ and $\mathrm{Mg}^{2+}$ was added to the sputum sample. The mixture placed on vortex for $10 \mathrm{sec}$ and then on the rocker for $30 \mathrm{~min}$. The sample was filtered through a $100 \mu \mathrm{m}$ filter to remove mucus. The filtrate has been centrifuged at $400 \times g$ for $10 \mathrm{~min}$ at $4^{\circ} \mathrm{C}$ to pellet the cells. Protein concentration was measured by Bradford's method. ${ }^{15,16}$ The supernatant was removed, aliquoted and stored at $-60^{\circ} \mathrm{C}$.

\section{Measurement of malondialdehyde}

Malondialdehyde (MDA) was measured using 2-thiobarbituric acid. Briefly, $50 \mu 1$ plasma are added to $640 \mu 1$ bidistilled water followed by the addition of $100 \mu \mathrm{l}$ thiobarbituric acid $(10 \mathrm{mg} / \mathrm{ml})$ and $60 \mu \mathrm{l}$ of $14 \% \mathrm{H}_{3} \mathrm{PO}_{4}$. Samples were heated for $45 \mathrm{~min}$ at $100^{\circ} \mathrm{C}$ and cooled down, then $850 \mu 1 n$-butanol were added. After precipitate formation, probes were centrifuged and absorbance of supernatants at 532 and $570 \mathrm{~nm}$ determined. The concentration of MDA was calculated using the formula:

$\operatorname{MDA}(\mu \mathrm{M})=\left(D_{\mathrm{s}}-D_{\mathrm{c}}\right) \times 102.6$

where $D_{\mathrm{s}}=$ absorbance at $532 \mathrm{~nm}$ - absorbance at $570 \mathrm{~nm}$ (for the plasma sample), $D_{\mathrm{c}}=$ absorbance at $532 \mathrm{~nm}$ - absorbance at $570 \mathrm{~nm}$ (for the control), and 
102.6 is a parameter that includes the extinction coefficient, the length of the light path, and the volume of the reaction mixture.

\section{Inhibition of PHA-induced lymphocyte proliferation by dexamethasone}

Mononuclear cells were isolated from heparinazed peripheral blood by Ficoll-Verographin density gradient centrifugation. The cells were washed twice in RPMI-1640 medium (ICN, USA) supplemented with $10 \%$ heat-inactivated donor horse serum, $2 \times 10^{-3} \mathrm{M}$ HEPES, $2 \mathrm{mM}$ L-glutamine, $2.8 \times 10^{-6} \mathrm{M} 2$-mercaptoethanol, and $20 \mu \mathrm{g} / \mathrm{ml}$ gentamycin. The cells were cultivated in flat-bottomed 96-well plates (Costar, USA), and contained $5 \times 10^{4}$ cells in each well. The final concentration of PHA (Sigma, USA) was $5 \mu \mathrm{g} / \mathrm{ml}$. Inhibition of PHA stimulation by dexametasone was evaluated at six different concentrations within the dose range of $10^{-10}$ to $10^{-6} \mathrm{M}$. Dexametasone was not added to the control wells (they contained a culture medium with or without PHA). The cells were incubated for $72 \mathrm{~h}$ at $37^{\circ} \mathrm{C}$ in a humidified atmosphere containing $5 \% \mathrm{CO}_{2}$. Four hours before the end of cultivation, each well was pulsed with $40 \mathrm{kBq}$ $\left[{ }^{3} \mathrm{H}\right]$-thymidine (Isotope, Russia). The cells were harvested with a cell harvester and counted on a liquid scintillation counter. Triplicate wells of each concentration were assayed and the counts per minute (count/min) were averaged. Percentage inhibition was calculated by dividing the count/min in each inhibited sample by the count/min in the sample containing PHA only, subtracting the background level (counts/ min in the wells with culture medium only) from these values. The intensity of suppression was estimated by probit analysis and expressed as $\mathrm{ED}_{50}$, i.e. a dose of immunosuppressive agent at which lymphocyte proliferation was $50 \%$ of its maximum. Previously, the direct positive correlation between the level of PHAinduced lymphocyte proliferation and of the inhibition degree of such stimulation by dexamethasone $\left(\mathrm{ED}_{50}\right)$ has been shown. On the basis of this correlation, we proposed the method of evaluation of individual susceptibility to the antiproliferative effect of glucocorticoids by $\Delta_{\mathrm{h}}$-parameter calculation. ${ }^{17} \Delta_{\mathrm{h}}$ was calculated using the formula:

$\Delta_{\mathrm{h}}=Y-Y^{\prime}$

where $Y=\log \mathrm{ED}_{50}, Y^{\prime}=0.447 X-4.399$, and $X=\ln$ (count/min)

\section{Assay of human leukocyte elastase activity}

The method is based on the ability of neutrophil elastase to interact with the specific chromogenic BANE ( $N$ - $t$-Boc-L-alanine $p$-nitrophenyl ester) (Reanal, Hungary) at acidic $\mathrm{pH}$, forming $p$-nitrophenol with a maximum of absorbance at $347.5 \mathrm{~nm} .{ }^{18,19}$ The standard assay was performed in $0.6 \mathrm{ml}$ solution containing an aliquot of sputum sample $(20-200 \mu \mathrm{l}), 0.01 \mathrm{M}$ BANE $(20 \mu \mathrm{l})$ and $0.05 \mathrm{M}$ sodium phosphate at $24^{\circ} \mathrm{C}$ and $\mathrm{pH}$ 6.5. Probes were assayed for absorbance at $347.5 \mathrm{~nm}$ for $12-15 \mathrm{~min}$. The absorbance per minute was then calculated. The amount of elastase was calculated using the formula:

Elastase activity $(\mathrm{U} / \mathrm{ml})=D_{347.5} \times 109 / V$

where $D_{347.5}$ is the absorbance per minute and $V$ is the volume of the sputum aliquot added; 109 is a parameter that includes the extinction coefficient, the length of the light path, and the volume of the reaction mixture. Under the specified conditions, one unit of human neutrophil elastase activity was that amount that hydrolyzed $1 \mathrm{nM}$ BANE per minute. Finally, the value of neutrophil elastase activity was normalized to the protein content in each sample of the sputum extract.

\section{Cytokine assays}

TNF- $\alpha$ activity was determined by the method of Ruff and Gifford ${ }^{20}$ with some modifications. Briefly, L929 cells were seeded at a density of $3 \times 10^{4}$ cells per well in 96-well plates in $100 \mu 1$ medium 199 to which $10 \%$ heat-inactivated calf bovine serum and gentamycin had been added. Plates were incubated at $37^{\circ} \mathrm{C}$ in a humidified atmosphere containing $5 \% \mathrm{CO}_{2}$ until the monolayer formation. After the culture medium elimination, twofold serial dilution of the samples $(100 \mu 1$ each dilution) and $100 \mu 1$ fresh culture medium with $20 \mu \mathrm{g} / \mathrm{ml}$ actinomycin D (Serva, Germany) were added, and further incubated for $18 \mathrm{~h}$ at the same conditions. Supernatants were then removed and cells stained with $0.2 \%$ crystal violet (Sigma, USA). After washing and drying, plates were finally read at $595 \mathrm{~nm}$ on a Titertek Multiskan microElisa reader. Human recombinant TNF- $\alpha$ (Institute of Bioorganic Chemistry, Moscow, Russia) was used as internal standard. For the comparison of experimental and calibrating curves, the probit-analysis method was used. TNF- $\alpha$ content in the samples was expressed in picograms per millilitre and normalized to the protein content in each sputum sample.

IL-8 was determined in the sputum samples using a commercially available enzyme-linked immunosorbent assay (Proteinovyi Kontur, St. Petersburg, Russia)

\section{Statistical analysis}

Statistical analysis was performed using non-parametric Wilcoxon tests. Correlation between plasma MDA and lymphocyte proliferation was analyzed using Spearman rank correlation. 
Table 1. Characteristics of the study subjects

\begin{tabular}{lccc}
\hline & Group A $(n=11)$ & Group B $(n=8)$ & $P$ value \\
\hline Age (years) & $12.8 \pm 0.6$ & $10.5 \pm 1.2$ & 0.25 \\
FEV $(\%$ pred.) & $56.7 \pm 6.2$ & $59.9 \pm 12.5$ & 0.83 \\
FVC (\% pred.) & $69.9 \pm 4.6$ & $74.5 \pm 8.6$ & 0.65 \\
W/H (\%) & $87.5 \pm 2.7$ & $75.2 \pm 2.0$ & 0.02 \\
\hline
\end{tabular}

Group A, Regular treatment with pancreatic enzyme replacement; group B, treatment with pancreatic enzyme replacement during period of hospitalization only. $\mathrm{FEV}_{1}$, forced expiratory volume in 1 sec; FVC, forced vital capacity; $\mathrm{W} / \mathrm{H}$, weight to height ratio; \% pred., percentage of predicted values. Differences between patient groups were analyzed using the unpaired Wilcoxon test. Data are presented as mean \pm SEM.

\section{Results}

\section{Characteristic of patients}

The patient group characteristics are summarized in Table 1 . Of the patients, 14 (74\%) were chronically colonized with $P$. aeruginosa. Assessment of nutritional status revealed that patients irregularly treated with pancreatic enzymes showed lower $\mathrm{W} / \mathrm{H}$ then those who were regularly received microspheric enzyme intakes $(75.2 \pm 2.0$ and $87.5 \pm 2.7$, respectively; $P=0.016)$. Thus, $\mathrm{W} / \mathrm{H}$ values between 70 and $82 \%$ were found in six children belonging to the group B $(n=8)$. In the same time, only four out of 11 patients from group A demonstrated the presence of malnutrition defined as $\mathrm{W} / \mathrm{H}<85 \%$. With regard to age and lung function failure, there were no significant differences between the patient groups.

\section{Plasma MDA levels in CF patients}

Figure 1 displays plasma MDA concentrations in $\mathrm{CF}$ patients during an exacerbation and after antibiotic treatment. For group A, plasma MDA levels during

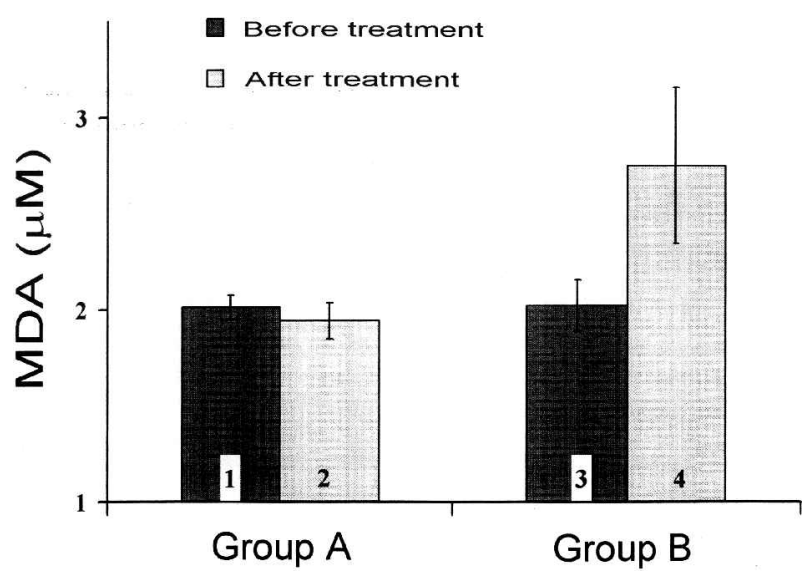

FIG. 1. Plasma malondialdehyde (MDA) levels in pancreatic insufficient cystic fibrosis patients before and after antibiotic treatment. Results are expressed as mean \pm SEM. A twosample Wilcoxon test was used to compare the means of MDA levels in a separate patient group before and after antibiotic treatment $\left(P_{3,4}=0.021\right)$. Differences in plasma MDA between patient groups were analysed using the unpaired Wilcoxon test $\left(P_{1,4}=0.017 ; P_{2,4}=0.016\right)$. acute lung exacerbation showed a median of $2.05 \mu \mathrm{M}$ (mean value, $2.02 \pm 0.06 \mu \mathrm{M}$ ). In group $\mathrm{B}$, MDA concentrations with median $1.89 \mu \mathrm{M}$ were situated in similar range $(2.02 \pm 0.13 \mu \mathrm{M} ; P=1)$. Antibiotic administration moderately decreased plasma MDA values in group A but this change did not reach significance $(1.94 \pm 0.10 \mu \mathrm{M} ; P=0.62)$. In the same time, plasma MDA levels in group B significantly increased with treatment and reached a median value of $2.51 \mu \mathrm{M}(2.75 \pm 0.40 ; P=0.021)$, which is much higher than that seen in group $A$ at exacerbation and recovery (both $P<0.017$ ).

\section{Proliferative response to PHA and lymphocyte susceptibility to glucocorticoids}

During acute lung exacerbation, the patients from group A had greater levels of T-cell proliferative response than $\mathrm{CF}$ subjects belonging to group $\mathrm{B}$ ( $P=$ 0.026; Fig. 2). The values expressed as uptake of ${ }^{3}[\mathrm{H}]$-thymidine were $82871 \pm 10924$ counts/min (group A) and $52255 \pm 5785$ counts/min (group B). Antibiotic administration did not induce any altera-

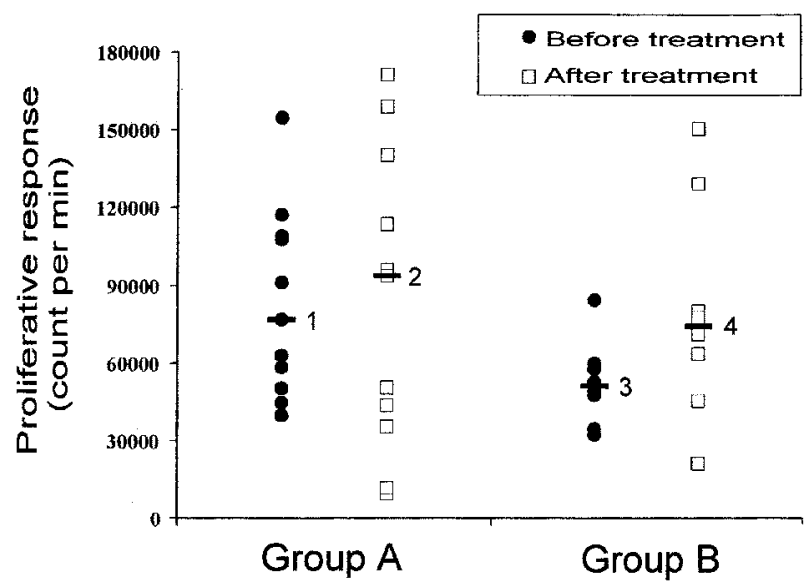

FIG. 2. PHA-induced T-lymphocyte proliferation in cystic fibrosis patients during lung exacerbation treatment. Results are given as count per minute. Median values are indicated by the lines. Each dot represents one patient. Data reported were compared by Wilcoxon test $\left(P_{1,3}=0.026\right)$. 


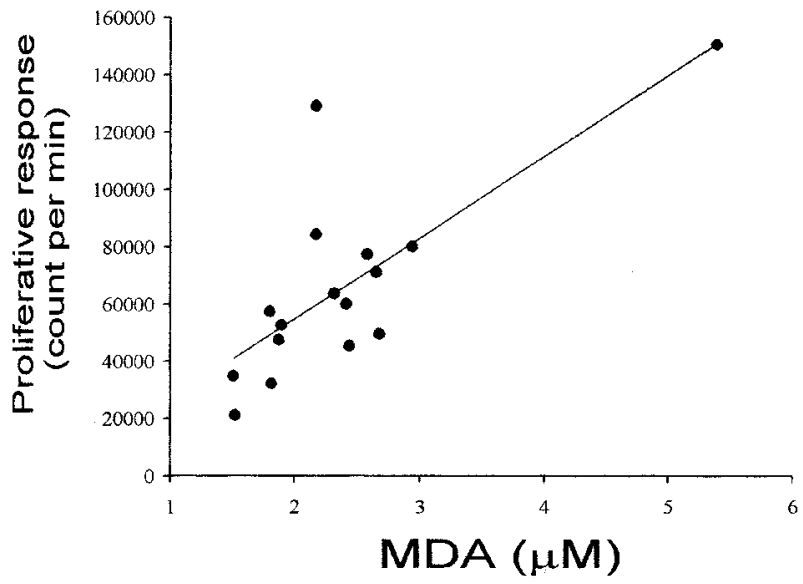

FIG. 3. Relationship between plasma malondialdehyde (MDA) and T-lymphocyte proliferation in the cystic fibrosis patients. The association were analyzed using the Spearmen rank correlation $(R=0.61, P=0.01)$.

tion in T-cell proliferative response in the patients regularly treated with pancreatic enzyme intakes $(84073 \pm 14890$ counts $/ \mathrm{min} ; P=0.95)$. At the same time, T-cell proliferative response to PHA in group B, lower at exacerbation, was increased during recovery (79715 \pm 14890 counts/min), but this change did not reach significance $(P=0.07)$. However, the levels of T-cell proliferation in the patients from groups $A$ and $B$ became statistically equivalent $(P=0.85)$. A significant positive linear association between values of plasma MDA and T-lymphocyte proliferation in the patients from group B has been observed (Fig. 3). For group A, the same correlation has not been found.

To evaluate individual susceptibility to glucocorticoids, the $\Delta_{\mathrm{h}}$ parameters were calculated as described in 'Materials and methods'. Patients were classified as steroid resistant if their $\Delta_{\mathrm{h}}$ parameters increased $>0$ and as steroid sensitive if this parameter failed to increase $>0$ (Fig. 4). During the acute lung exacerbation, peripheral blood lymphocytes of patients from group B demonstrated the resistance to antiproliferative action of dexametasone $\left(\Delta_{\mathrm{h}}=0.48 \pm\right.$

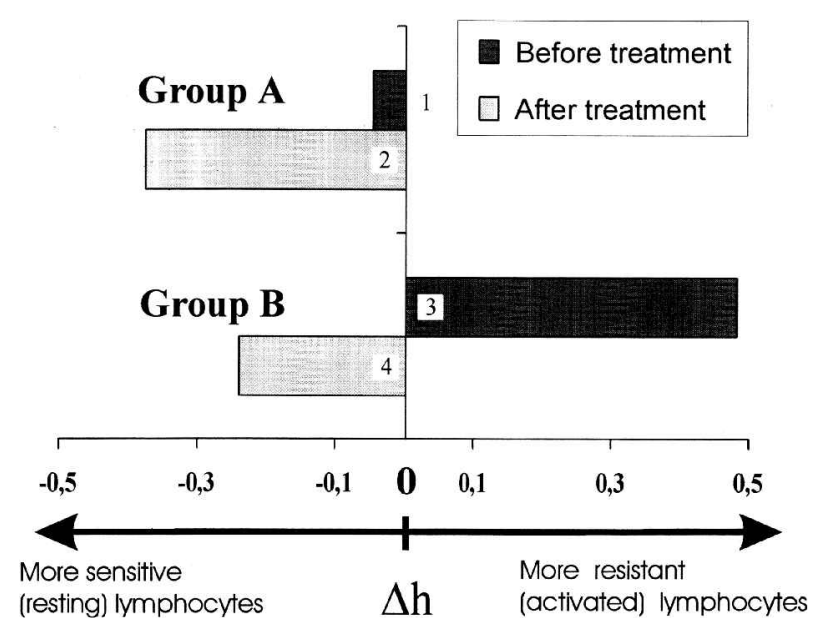

FIG. 4. Peripheral blood lymphocyte susceptibility to steroid suppression. Inhibition degree of PHA-induced lymphocyte proliferation by different concentrations of dexamethasone was evaluated. The cell sensitivity is presented as the mean of the $\Delta_{\mathrm{h}}$ value $\left(P_{1,2}=0.068, P_{3,4}=0.030\right.$, two-sample Wilcoxon test; $P_{1,3}=0.035$, unpaired Wilcoxon test).

0.15). In contrast, the patients from group A were relatively steroid sensitive $\left(\Delta_{\mathrm{h}}=-0.05 \pm 0.14\right)$. There were statistically significant differences between the groups $(P=0.035)$. Following treatment, both patient groups showed the switch from steroid resistance to steroid sensitivity. However, patients from group B demonstrated a statistically significant increase in lymphocyte sensitivity to steroid suppression $\left(\Delta_{\mathrm{h}}=\right.$ $-0.24 \pm 0.18 ; P<0.03)$. For group A, the change in $\Delta_{\mathrm{h}}$ values did not reach significance $\left(\Delta_{\mathrm{h}}=-0.37 \pm 0.20\right.$; $P=0.07$ ).

\section{In situ inflammatory markers}

During acute lung exacerbation, elevated elastase activity, high amounts of IL-8 and TNF- $\alpha$, and increased protein concentrations have been observed in the sputum samples from patients of both groups (Table 2). However, in the regularly treated patients, all indexes of inflammation were clearly higher than those in children who irregularly received pancreatic enzyme supplement. Antibiotic treatment failed to

Table 2. In situ inflammatory markers in patients with cystic fibrosis during an exacerbation and after antibiotic treatment

\begin{tabular}{|c|c|c|c|c|c|c|}
\hline & \multicolumn{3}{|c|}{ Group A $(n=11)$} & \multicolumn{3}{|c|}{ Group B $(n=8)$} \\
\hline & $\begin{array}{l}\text { Before } \\
\text { treatment }\end{array}$ & $\begin{array}{c}\text { After } \\
\text { treatment }\end{array}$ & $\begin{array}{c}P \\
\text { value }\end{array}$ & $\begin{array}{l}\text { Before } \\
\text { treatment }\end{array}$ & $\begin{array}{c}\text { After } \\
\text { treatment }\end{array}$ & $\begin{array}{c}P \\
\text { value }\end{array}$ \\
\hline Elastase activity (U/mg protein) & $28.5 \pm 5.7$ & $45.0 \pm 10.8$ & 0.14 & $16.6 \pm 4.1$ & $13.2 \pm 7.1^{*}$ & 0.61 \\
\hline IL-8 (ng/mg protein) & $6.0 \pm 1.0$ & $5.8 \pm 0.7$ & 0.89 & $5.4 \pm 0.9$ & $4.0 \pm 1.1$ & 0.41 \\
\hline TNF- $\alpha$ (ng/mg protein) & $2.1 \pm 1.0$ & $2.3 \pm 0.9$ & 0.89 & $1.2 \pm 0.8$ & $1.0 \pm 0.7$ & 0.83 \\
\hline Protein $(\mathrm{mg} / \mathrm{ml})$ & $3.3 \pm 0.8$ & $3.0 \pm 0.7$ & 0.82 & $1.3 \pm 0.3^{*}$ & $1.5 \pm 0.6$ & 0.75 \\
\hline
\end{tabular}

Group A, Regular treatment with pancreatic enzyme replacement; group B, treatment with pancreatic enzyme replacement during period of hospitalization only. Data are presented as mean \pm SEM. ${ }^{*} P<0.05$ compared with the corresponding mean of patients from group $A$ (unpaired Wilcoxon test). 
decrease elevated values of in situ inflammatory markers. In both patient groups, all indexes of inflammation were situated within the same range as at the exacerbation period.

\section{Discussion}

CF patients are regularly exposed to increased oxidative stress, which appears to be a consequence of chronic pulmonary inflammation rather then part of the primary cystic fibrosis defect. ${ }^{21}$ Due to chronic basal free radical attack, their exhausted antioxidant defenses are unable to recover in the spaces between exacerbations. ${ }^{22}$ In addition, deficiency of systemic scavengers may be aggravated by malabsorption of fatsoluble antioxidants secondary to pancreatic insufficiency. ROS produced by activated phagocytes are important in the killing of pathogens, but may damage host tissues attacking structural phospholipids, proteins, carbohydrates and DNA. ${ }^{23}$ The main lipid targets of free radicals are the PUFAs of membrane phospholipids that undergo peroxidation, resulting in the formation of lipid hydroperoxides and their degradation products such as MDA. ${ }^{24}$ Thereafter, increased free radical damage associated with acute lung exacerbation may be reflected in the elevated plasma MDA levels. Antibiotic treatment reduces lung inflammation, which should result in decreased oxygen radical production. Accordingly, for the patients from group A, a mild reduction in plasma MDA concentrations compared with pretreatment levels has been observed. In contrast, plasma MDA levels in group B did increase significantly following treatment, indicating oxidative lipid damage during clinical resolution. This finding seems, at first, to contrast with those from trials that consider the elevated plasma MDA level as one of the signs of ongoing infection. ${ }^{22,25}$ However, increased plasma MDA concentration is a consequence of free radical damage in the circulation and cannot reflect solely those processes occurring in bronchi.

Elevated MDA levels in group B may be interpreted as systemic evidence of increased oxidative stress. The patients were started on the microspheric enzymes at a time of acute lung exacerbation when their susceptibility to oxidative stress was markedly increased. Adequate enzyme replacement improved nutrient absorption, which should result in elevation of plasma PUFAs, lipoprotein and cholesterol concentrations. In this way, new lipid targets of free radicals have suddenly appeared in the circulation, and the exhausted system of antioxidant defense was unable to prevent their oxidation.

Improvement in fat absorption and associated oxidative stress might be relevant to the increase in T-cell proliferation that occurred in group B (but not in group A) after the treatment. Thus, accumulating data suggest that oxidants and pro-inflammatory PUFAs can enhance cytokine production and effects, thereby contributing to lymphocyte activation. ${ }^{13,26}$ The proposal is also confirmed by a significant positive linear association between the level of lymphocyte proliferation and plasma MDA concentration in CF patients from group $B$.

There are a large number of other potential mechanisms that may regulate T-lymphocyte proliferation. Some of them relate to alteration of the composition of membrane phosopholipids and, as a consequence, membrane fluidity. Changes in membrane fluidity may interrupt binding of cytokines to their receptors and/or activity of $G$ proteins. ${ }^{27}$ On the other hand, since phosphoinositide, a minor membrane phosopholipid, seems to be the major source of the second messengers participating in T-cell receptor signalling, its deficiency due to impaired uptake of dietary lipids may reduce T-cell activation and proliferative response. ${ }^{28}$ Anyway, improvement in fat absorption might restore appropriate membrane composition in CF tissues and normalize the lymphocyte activity.

The comparison of in situ inflammatory markers (TNF- $\alpha$ and IL-8 levels, neutrophil elastase activity and protein content) did not reveal statistically significant differences between the patient groups. However, each marker of airway inflammation was increased in the sputum of children from group A compared with patients from group B (see Table 2). It is possible that soft inflammatory response in malnourished patients was related to poor nutritional status. This is in accordance with recent trials showing the strong relationships between nutrient deficiency and immune response. ${ }^{29,30}$ However, our previous study suggested that in situ inflammatory markers in CF patients were closely related to their $P$. aeruginos $a$ status. It has been shown that the patients chronically colonized with $P$. aeruginosa for 2 years or more exhibited increased inflammatory parameters compared with uninfected patients or children with short-term colonization. ${ }^{31}$ Individual analyses of $P$. aeruginosa status revealed that five patients from group A $(n=11)$ and only two patients from group $\mathrm{B}(n=8)$ exhibited long-term colonization with pathogens. At the same time, three patients from group B and only one patient from group A were without $P$. aeruginosa infection.

The poor $P$. aeruginosa status of group $\mathrm{A}$ is confirmed by evaluation of individual susceptibility to glucocorticoids (the $\Delta_{\mathrm{h}}$ parameter, see Fig. 4). Relatively low lymphocyte sensitivity to steroid suppression at a period of acute lung exacerbation $\left(\Delta_{\mathrm{h}} \sim 0\right)$ is a systemic evidence of permanent airway infection in this patient group. ${ }^{31}$ The patients of group B demonstrated significant resistance to antiproliferative action of glucocorticoids $\left(\Delta_{\mathrm{h}}>0\right)$. Such resistance is associated with the systemic inflammatory response to acute infection and accompanied by the increase in number of activated lymphocytes in the circulation. Change from steroid resistance to steroid sensitivity of 
lymphocytes $\left(\Delta_{\mathrm{h}}<0\right)$ observed in both groups after treatment shows that antibiotics are able to restrict the acute infection in CF lungs and suppress the systemic inflammatory response.

This study provides the evidence that acute lung exacerbation in malnourished CF patients who had irregularly received pancreatic enzyme supplements is associated with a significant alteration in T-cell activity. Antibiotic therapy and adequate enzyme replacement improve lymphocyte function but lead to an increase in systemic oxidative stress. In the circumstances, an extra aggressive antioxidant course in addition to conventional treatment can be recommended. Our results also suggested that measurement of inflammatory mediators in the sputa of CF patients with chronic $P$. aeruginosa infection is not helpful for identifying acute respiratory exacerbation. At the same time, the infectious inflammatory-immune process in the lung could be measured in peripheral blood. Thus, the assessment of individual susceptibility to glucocorticoids (the $\Delta_{\mathrm{h}}$ parameter) may be useful to confirm acute lung exacerbation and monitor the efficacy of antibiotic treatment.

\section{References}

1. Koch C, Høiby N. Pathogenesis of cystic fibrosis. Lancet 1993; 341: 1065-1069.

2. Saiman L. Treatment of infections in patients with cystic fibrosis. Infect Med 1993; 10: 37-43.

3. Konstan MW, Hillard KA, Norvell TM, Berger M. Bronchoalveolar lavage findings in cystic fibrosis patients with stable, clinically mild lung disease suggest ongoing infection and inflammation. Am J Respir Crit Care Med 1994; 150: 448-454.

4. Van Delden C, Iglewski BH. Cell-to-cell signaling and Pseudomonas aeruginosa infections. Emerging Infect Dis 1998; 4: 551-560.

5. Suter S, Schad JM, Roux I. Granulocyte neutral proteases and Pseudomonas elastase as possible causes of airway damage in patients with cystic fibrosis. J Infect Dis 1984; 149: 523-531.

6. Brown RK, Kelly FJ. Role of free radicals in the pathogenesis of cystic fibrosis. Thorax 1994; 49: 738-742.

7. Durieu I, Peyrol S, Gindre D, Bellon G, Durand DV, Pacheco Y. Subepithelial fibrosis and degradation of the bronchial extracellular matrix in cystic fibrosis. Am J Respir Crit Care Med 1998; 158: $580-586$.

8. Lewis MI, Belman MJ. Nutrition and respiratory muscles. Clin Chest Med 1988; 9: 37-48.

9. Borowitz D. The interrelationship of nutrition and pulmonary function in patients with cystic fibrosis. Curr Opin Pulmon Med 1996; 2: 457-461.
10. Durie PR, Pencharz PB. Cystic fibrosis: nutrition. Br Med Bull 1992; 48 : 823-846.

11. Yu H, Nasr SZ, Deretic V. Innate lung defenses and compromised Pseudomonas aeruginosa clearance in the malnourished mouse model of respiratory infection in cystic fibrosis. Infect Immun 2000; 68: 2142-2147.

12. Wilson DC, Pencharz PB. Nutrition and cystic fibrosis. Nutrition 1998; 14: $792-795$.

13. Baeuerle PA, Henkel T. Function and activation of NF-kappa B in the immune system. Annu Rev Immunol 1994; 12: 141-179.

14. Clandinin MT. Infant nutrition: effects of lipid on later life. Curr Opin Lipidol 1995; 6: 28-31.

15. Bradford MM. Ann Biochem 1976; 72: 248-254.

16. Brogdon WG, Dickinson CM. Ann Biochem 1983; 131: 499-503.

17. Pukhalsky AL, Kalashnikova EA, Lyashko VN, Pevnitsky LA. Inhibition of phytohemagglutinin-induced lymphocyte proliferation by dexamethasone: mechanisms of individual susceptibility. Int J Immunopharmac 1990; 12: 657-663.

18. Visser L, Blout ER. The use of $p$-nitrophenyl- $N$-tetrabutoycarbonylL-alaninate for elastase. Bichem Biophys Acta 1972; 268: 257-260.

19. Kaminskaya GA, Zhukova NL, Stepanyan IE. Comparison of two methods for the study of the sputum elastolytic activity and assessment of the results. Lab Delo 1984; 2: 110-113 (in Russian).

20. Ruff MR, Gifford GE. Tumor necrosis factor. In: Pick E, ed. Lymphokines. New York: Academic Press, 1981: 235-241.

21. Hull J, Vervaart P, Grimwood K, Phelan P. Pulmonary oxidative stress response in young children with cystic fibrosis. Thorax 1997; 52: 557-560.

22. McGrath LT, Mallon P, Dowey L, Silke B, McClean E, McDonnell M, Devine A, Copeland S, Elborn S. Oxidative stress during acute respiratory exacerbations in cystic fibrosis. Thorax 1999; 54: 518-523.

23. Reilly PM, Schiller HJ, Bulkley GB. Pharmacologic approach to tissue injury mediated by free radicals and other oxygen metabolites. Am J Surg 1991; 161: 488-503.

24. Tribble DL, Yee AWT, Jones DP. The pathophysiological significance of lipid peroxidation in oxidative cell injury. Hepatology 1976; 7 : 377-387.

25. Nowak D, Zieba M, Zawiasa D, Rozniecki J, Krol M. Changes of serum concentration of lipid peroxidation products in patients with pneumonia. Monaldi Arch Chest Dis 1996; 51: 188-193.

26. Grimble RF, Tappia PS. Modulation of pro-inflammatory cytokine biology by unsaturated fatty acids. Z Ernabrungswiss 1998; 37 (Suppl 1): 57-65.

27. Raber J, Bast A. Changes in receptor response by the effect of disease on membrane fluidity. Med Hypothesis 1989; 28: 169-171.

28. Scholz W, Isakov N, Mally MI, Theofilopoulos AN, Altman A. Lpr T cell hyporesponsiveness to mitogens linked to deficient receptor-stimulated phosphoinositide hydrolysis. J Biol Chem 1988; 263: 3626-3631.

29. Schoenherr WD, Jewell DE. Nutritional modification of inflammatory diseases. Semin Vet Med Surg (Small Anim) 1997; 12: 212-222.

30. Zuin G, Principi N. Trace elements and vitamins in immunomodulation in infancy and childhood. Eur J Cancer Prev 1997; 6 (Suppl 1): S67-S69.

31. Pukhalsky AL, Kapranov NI, Kalashnikova EA, Shmarina GV, Shabalova LA, Kokarovtseva SN, Pukhalskya DA, Kasirskaja NJ, Simonova OI. Inflammatory markers in cystic fibrosis with lung Pseudomonas aeruginosa infection. Med Inflam 1999; 8: 159-167.

Received 28 December 2000; accepted 31 January 2001 


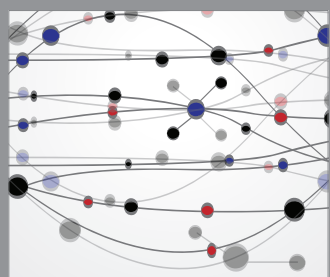

The Scientific World Journal
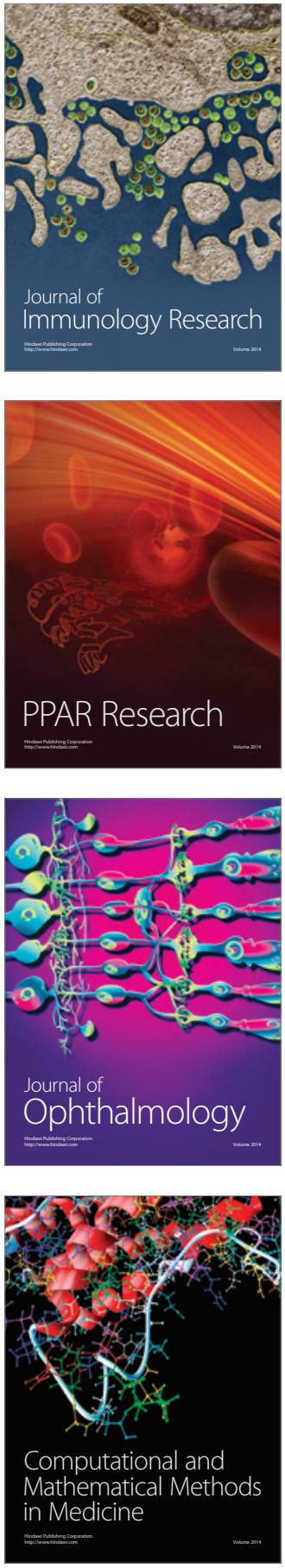

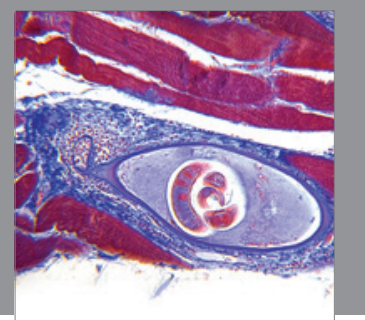

Gastroenterology

Research and Practice
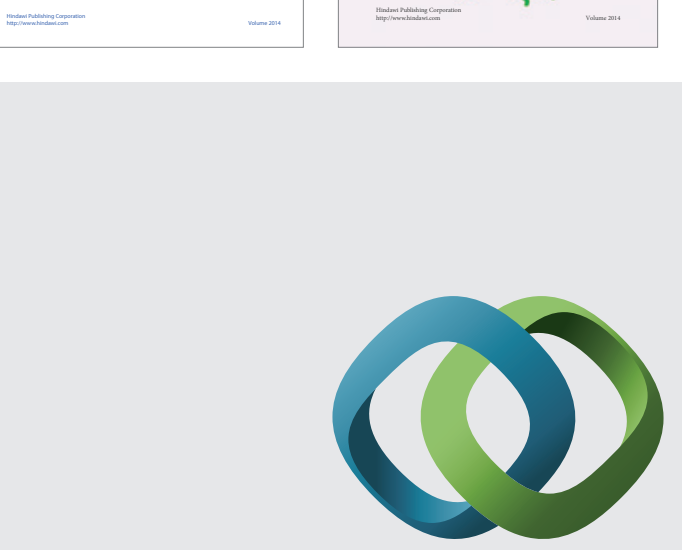

\section{Hindawi}

Submit your manuscripts at

http://www.hindawi.com
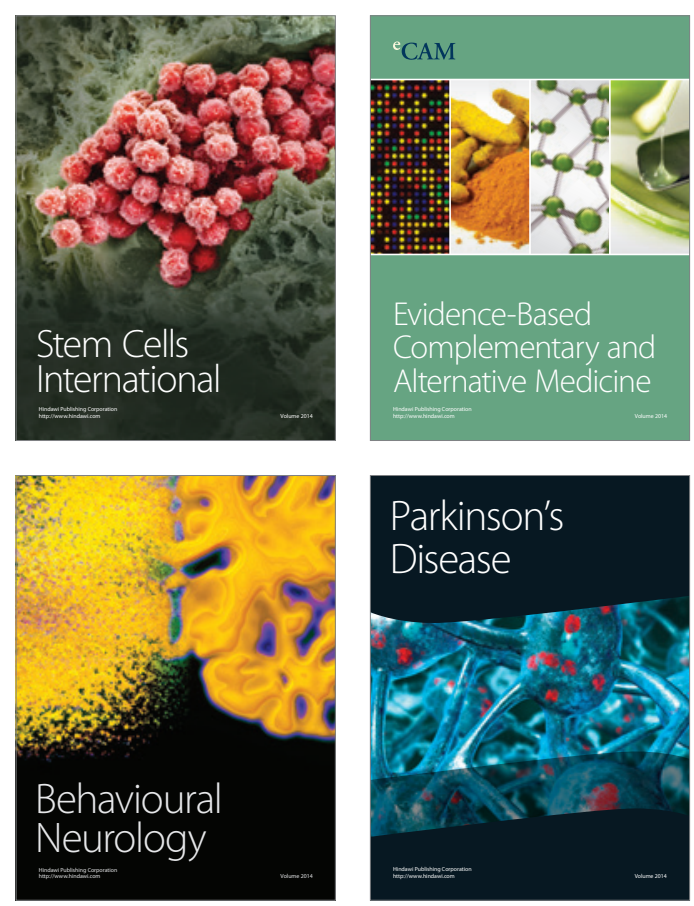

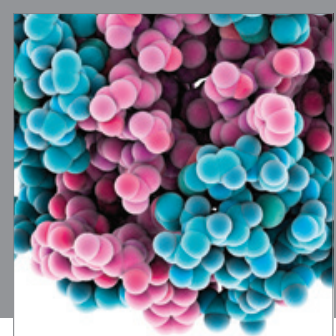

Journal of
Diabetes Research

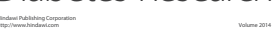

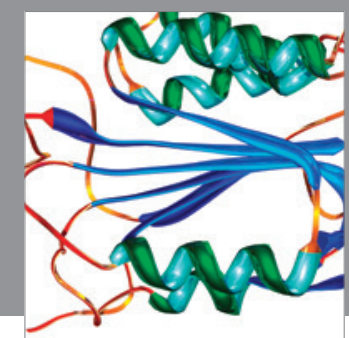

Disease Markers
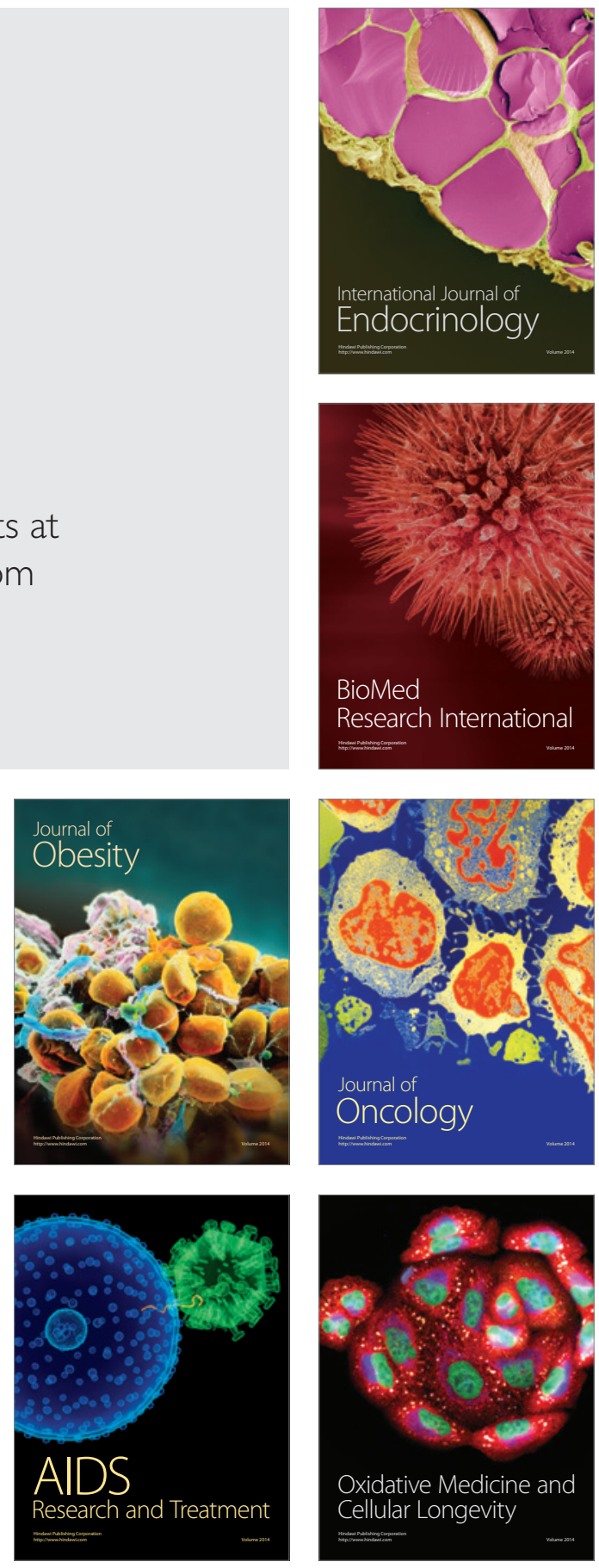